\title{
Diagnosis and Counseling of Fetal Mild Ventriculomegaly
}

\author{
${ }^{1}$ Vincenzo D'Addario, ${ }^{2} \mathrm{M}$ Cialdella, ${ }^{3} \mathrm{G}$ Volpe
}

\begin{abstract}
Mild ventriculomegaly (MVM) is defined as a lateral ventricular diameter measured at the level of the atrium of $\geq 10 \mathrm{~mm}$ but $<15 \mathrm{~mm}$. Prenatal evaluation includes targeted sonographic examination for central nervous system (CNS) and extraCNS abnormalities (present in $41.4 \%$ of the cases), and diagnostic amniocentesis for chromosomal analysis (3\% of chromosomopaties in isolated cases) and infectious disease studies $(1.5 \%$ incidence). Individualized patient counseling is based on these test results. Optimal postnatal care involves appropriate pediatric neurologic and developmental specialists.
\end{abstract}

Learning objectives: After completion of this article, the reader will be able to define the normal appearance and size of the fetal cerebral ventricles, to list the conditions associated with $\mathrm{MVM}$, and to counsel the parents properly.

Keywords: Fetus, Neurodevelopmental delay, Ultrasound, Ventriculomegaly

How to cite this article: D'Addario V, Cialdella M, Volpe G. Diagnosis and Counseling of Fetal Mild Ventriculomegaly. Donald School J Ultrasound Obstet Gynecol 2016;10(2):154-159.

\section{Source of support: Nil}

\section{Conflict of interest: None}

Ventriculomegaly (VM) is a condition characterized by an enlargement of lateral ventricles of the developing fetal brain which affects 1 to 2 in 1,000 births. ${ }^{1}$ Fetal cerebral lateral ventricles are measured during fetal anomaly scan performed in the second trimester to screen for malformations. The measurement is done at the level of the atrium of the lateral ventricle filled by the echogenic choroid plexus, visible in an axial plane of the fetal brain showing also the frontal horns of the lateral ventricles and the cavum septi pellucidi. The calipers are positioned on the internal margin of the medial and lateral walls of the atria, at the level of the glomus of the choroid plexus, perpendicular to the long axis of the lateral ventricle. ${ }^{2,3}$

In order to standardize the correct technique of measurement. the following criteria should be fulfilled ${ }^{4}$ :

\footnotetext{
${ }^{1}$ Associate Professor, ${ }^{2,3}$ Postgraduate student

${ }^{1-3}$ Department of Obstetrics and Gynecology, University Medical School of Bari, Bari, Italy

Corresponding Author: Vincenzo D'Addario, Associate Professor, Department of Obstetrics and Gynecology, University Medical School of Bari, Piazza G. Cesare, 70124 Bari, Italy e-mail: vincenzo.daddario@uniba.it
}

- Midline structures should be equidistant from the proximal and distal calvarium margins

- The cavum septi pellucidi should be visualized as the anterior landmark and the ambient cistern as the posterior landmark

- The measurement should be performed opposite the internal parieto-occipital sulcus

- The measurement should be perpendicular to the inner and outer borders of the ventricle

- The measurement should be done on the inner edges of the ventricular walls.

An atrial width of less than $10 \mathrm{~mm}$ is considered normal (Fig. 1A). Ventriculomegaly is diagnosed when the width of one or both lateral ventricles, measured according to the criteria described so far, is $\geq 10 \mathrm{~mm}$.

Measurements between $\geq 10$ and $<15 \mathrm{~mm}$ constitute mild VM (MVM) (Fig. 1B), while values $\geq 15 \mathrm{~mm}$ represent
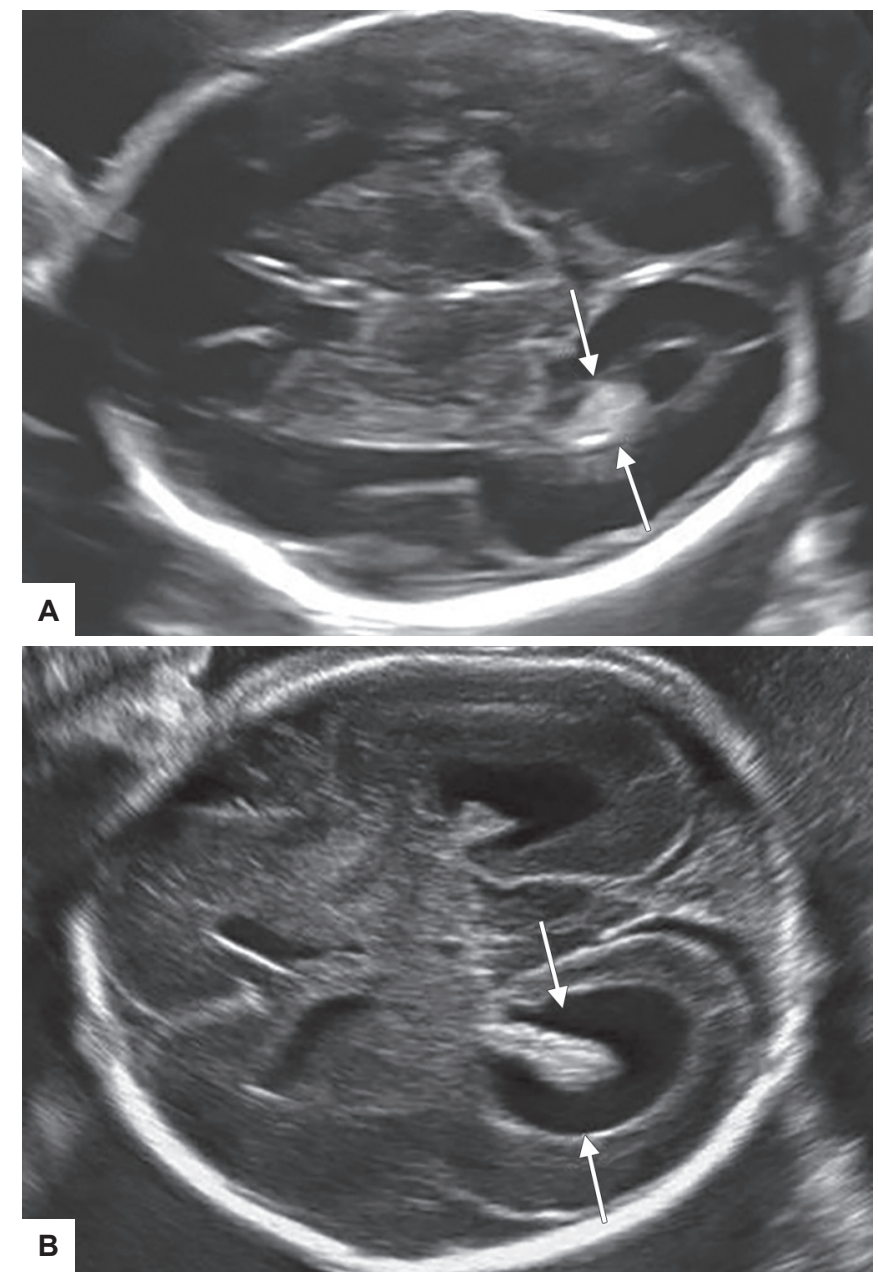

Figs $1 A$ and $B$ : Correct technique of measurement of the atrial width: (A) normal ventricle; and (B) mild ventriculomegaly 
severe VM. ${ }^{2,3}$ Mild ventriculomegaly is also defined as borderline VM. ${ }^{5}$ Some authors ${ }^{6}$ use the term "milder VM" and "moderate VM" to indicate measurements of 10 to 12 and 12.1 to $14.9 \mathrm{~mm}$ respectively. Other authors ${ }^{7}$ restrict the term of MVM to measurements between 10 and $12 \mathrm{~mm}$.

Mild ventriculomegaly can be unilateral or bilateral, symmetrical or asymmetrical, isolated or associated with central nervous system (CNS) or extraneural anomalies, chromosomal abnormalities, congenital infections, and hemorrhages.

\section{MILD VENTRICULOMEGALY ASSOCIATED WITH OTHER PATHOLOGIES}

\section{Neural and Extraneural Anomalies}

Mild ventriculomegaly may be associated with neural and extraneural anomalies. For this reason, an accurate neurosonographic examination should be performed by experienced operators in a reference center. The percentage of associated anomalies ranges from 10 to $71 \%$ with an average value of $41.4 \% .^{5,7-9}$ As regards the CNS abnormalities, some of them may be easily recognized, such as open spinal defect or Dandy-Walker malformation. ${ }^{10}$ Subtle anomalies, such as dysgenesis of the corpus callosum (Fig. 2) or velum interpositum cyst or neuronal migration and proliferation disorders (Fig. 3) may require an accurate evaluation or may even be missed. ${ }^{11}$

A recent meta-analysis ${ }^{8}$ shows that $7.4 \%$ of neural anomalies is not recognized at the time of the initial presentation, in contrast with the percentages previously reported in two different reviews (10-12\% respectively). ${ }^{12,13}$ This lower percentage is mainly due to the improvement of ultrasound diagnostic capabilities and of operator training. The abnormalities which still are missed are mainly represented by neuronal migration and proliferation disorders which usually develop later in the third trimester. For this reason, magnetic resonance imaging (MRI) plays an important role in evaluating fetuses with MVM when this kind of anomalies are suspected. ${ }^{14-16}$

\section{Chromosomal Abnormalities}

Ultrasound finding of MVM should raise the suspicion of chromosomal abnormalities, mainly trisomy 21, since several studies have demonstrated a percentage of association with abnormal karyotype ranging from
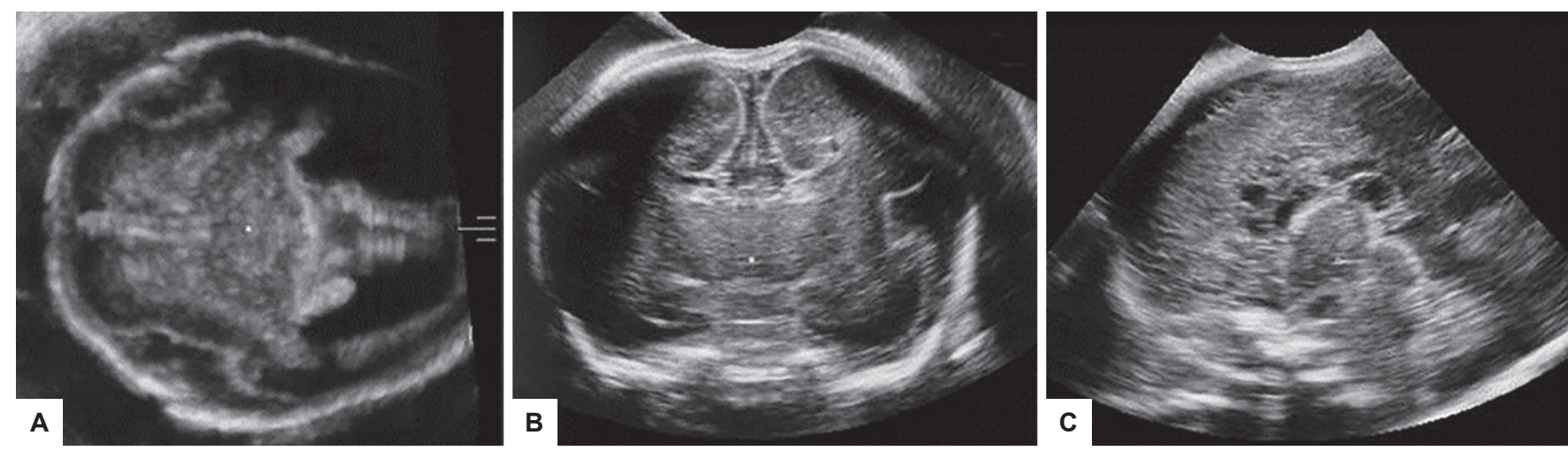

Figs 2A to C: Mild ventriculomegaly associated with agenesis of corpus callosum: (A) axial view; (B) coronal view; and (C) sagittal view

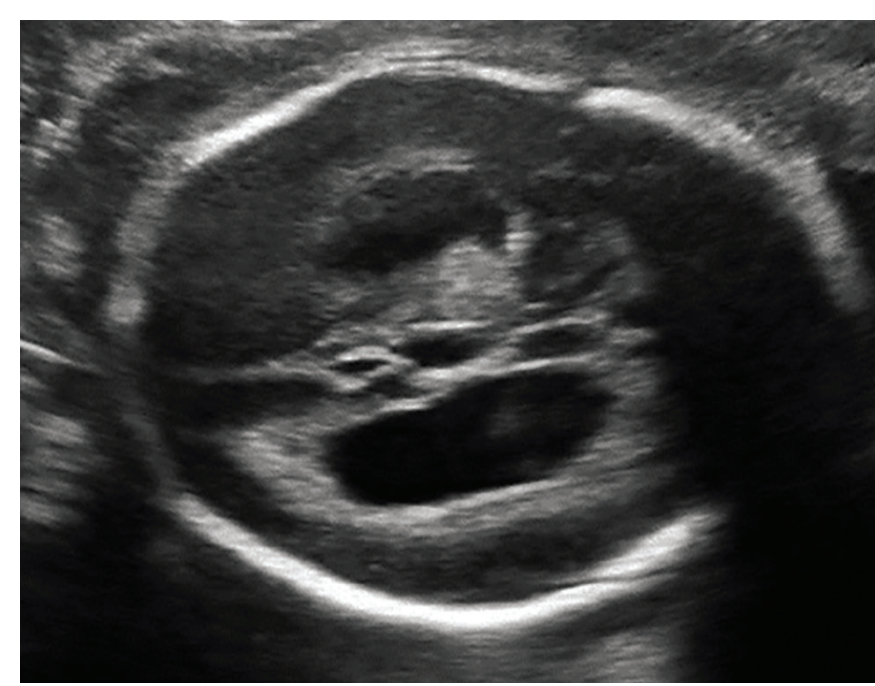

Fig. 3: Mild ventriculomegaly associated with microlissencephaly
0 to $28.6 \%$ with an average value of $2.8 \% .{ }^{12} \mathrm{~A}$ more recent review by Pagani et $\mathrm{al}^{8}$ reports a prevalence of abnormal karyotype of $4.7 \%$ in the whole cohort of VM, with a value of $8.3 \%$ in cases with associated anomalies and 3\% in isolated MVM. This wide variation of results may depend on the prevalence of trisomies in the studied population. Given the strong association between MVM and chromosomal abnormalities, invasive testing for chromosomal analysis should be offered to all patients. ${ }^{12}$ However, the correlation between MVM and chromosomal abnormalities is still a cause of debate.

\section{Congenital Infections}

Congenital infections (toxoplasmosis, cytomegalovirus (CMV) and Rubella) can be a cause of MVM, with a 

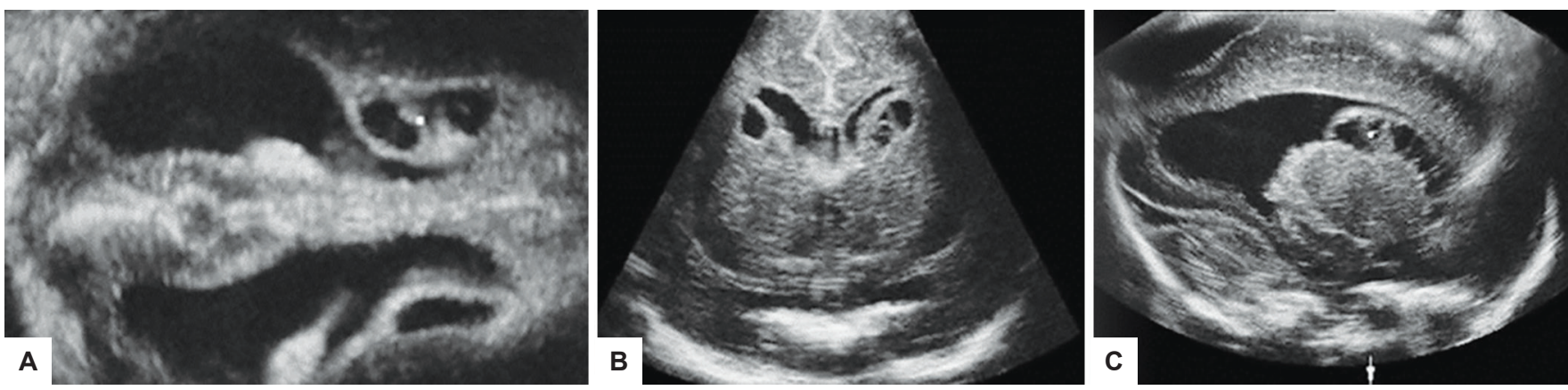

Figs 4A to C: Mild ventriculomegaly associated with subependimal cysts in a case of CMV infection: (A) axial view;

(B) coronal view; and (C) sagittal view

mean percentage of $1.5 \% .{ }^{13}$ In fetuses with proven CMV infection, VM is the most common ultrasound finding, being present in $18 \%$ of cases. In the majority of cases, other sonographic signs may be observed in the fetal brain, such as small periventricular calcifications or small subependimal cysts (Fig. 4) and in extraneural structures, such as liver calcifications, ascites, hepatosplenomegaly, echogenic bowel, placentomegaly, growth restriction. ${ }^{17-21}$ When VM is diagnosed, screening for infections (usually TORCH) is recommended ${ }^{5,22,23}$ for the safety, simplicity, and relative low cost of execution of these tests.

In doubtful cases, MRI can provide important additional information with regard to subtle cerebral signs of infections, such as abnormal gyration, cerebellar hypoplasia, or abnormal signal in white matter. ${ }^{19}$

\section{Feto-neonatal Alloimmune Thrombocytopenia}

Fetal and neonatal alloimmune thrombocytopenia is an alloimmune disorder resulting from platelet opsonization by maternal antibodies that destroy the fetal platelets. This rare condition implies a risk of intracranial hemorrhage and VM of about 10 to $30 \%{ }^{24}$ In these cases, VM is usually associated with other sonographic findings, such as hyperechogenicity of the ventricular walls or with the presence of intraventricular echogenic material, as a sign of the hemorrhage. For this reason, the search for antiplatelet antibodies is suggested when VM is associated with signs of intracranial hemorrhage.

\section{ISOLATED MILD VENTRICULOMEGALY}

Isolated mild ventriculomegaly (IMVM) is a diagnosis of exclusion, characterized by the sonographic absence of other associated malformations or markers of aneuploidy at the time of the initial presentation. . $^{5,25}$ The prevalence of IMVM is extremely variable and has been reported ranging from 0.15 to $0.7 \%{ }^{22,26}$ Isolated mild ventriculomegaly can involve one or both lateral ventricles with no significant differences in terms of neurodevelopment outcome. Moreover, some authors classify bilateral isolated forms into symmetrical and asymmetrical, defining the latter as difference in width of $>2 \mathrm{~mm} .{ }^{9}$ These cases seem to carry a worse neurological outcome.

Isolated mild ventriculomegaly remains stable during pregnancy in $55 \%$ of the cases, increases in $15.7 \%$, and decreases in $34 \%{ }^{12}$

Fetuses with apparent IMVM should be sent to a referral center with the aim of performing a detailed anomaly scan and neurosonographic evaluation.

In these cases, fetal karyotyping should also be offered $^{12,27}$ and maternal serum screening for CMV, toxoplasma and Rubella should be considered. ${ }^{12,17,19,28}$

The timing and frequency of the follow-up depend on the gestational age and on the protocol used by the different centers. A minimal time before performing a follow-up after the first diagnosis is 2 weeks, since a shorter time interval would not allow to evidence the possible variation in the size of the ventricles. ${ }^{29}$

Isolated mild ventriculomegaly may also be the first sign of brain anomalies recognizable only in the third trimester or even after delivery. For this reason, a MRI between 30 and 32 weeks of gestation should be suggested with the aim of adding information about cortical anomalies. ${ }^{14,15}$

\section{NEURODEVELOPMENTAL DELAY IN IMVM}

The short- and medium-term postnatal outcomes of fetuses with IMVM show a slightly higher incidence of neurodevelopmental delay as compared with the normal population. . $^{60-32}$

Pagani et $\mathrm{l}^{8}$ report a prevalence of neurodevelopmental delay of $7.9 \%$; this value is sensibly lower as compared with results of previous studies by Melchiorre et $\mathrm{al}^{12}$ and Devaseelan et $\mathrm{al}^{13}$ (10.9 and $12 \%$ respectively); however, it is just slightly increased in comparison with the 2 to $3 \%$ estimated for childhood disability in the general population. ${ }^{33}$

The lower prevalence reported in the most recent review may depend on the improvement of sonographic 
techniques that allow the prenatal diagnosis of anomalies associated with MVM, which in the past were often missed leading to a worse prognosis.

Lyall et $\mathrm{al}^{34}$ analyzed the natural history of prenatal diagnosed IMVM in early childhood demonstrating a persistent enlargement of the lateral ventricle volume through 2 years of age. These children got a lower score on the fine motor and expressive language subscales of the Mullen Scale of Early Learning in comparison with the control group. In this way, the authors support the hypothesis that prenatal diagnosis of IMVM should be used as early biomarker of abnormal postnatal brain development.

It is very difficult to define with accuracy the neurological outcome in cases of IMVM because the literature shows conflicting results depending on the inadequate qualitative assessment and the different protocols used to assess postnatal neurological development, on the short period of follow-up planned, on the different ages of infants analyzed, and on the absence of distinction between mild, moderate, and severe delay. ${ }^{29}$ The evaluation of the neurodevelopmental delay in preschool children should include examination of locomotor activity, hearing, speech capacity, eye and hand coordination, and learning performance.

Although some authors suggested that other factors, such as female sex, ${ }^{5}$ asymmetrical bilateral IMVM, ${ }^{6,30}$ and early presentation during the pregnancy, ${ }^{35}$ may worsen the neurological outcome, all available data prove that in IMVM the most important prognostic factors are the association with other abnormalities not detected at first examination and the progression of ventricular dilatation, both of which are retrospective diagnoses. ${ }^{12}$

The neurodevelopmental delay in cases of isolated progressive VM is $16.7 \%$; in this group of fetuses, there is also the highest incidence of chromosomal abnormalities $(22.2 \%)$ and associated anomalies $(71.4 \%)$; the overall abnormal outcome is $44.4 \%$. $6,12,26,36-42$

From the above considerations, it is evident that in order to evaluate exactly the contribution of IMVM to the neurodevelopmental delay in infancy, a large collaborative prospective study using a unified protocol and long-term objective postnatal follow-up is needed. ${ }^{29}$

\section{COUNSELING}

The sonographic finding of fetal MVM still represents a challenge in terms of management, counseling, prognosis, and postnatal neurological development because at the time of first diagnosis it is not always possible to rule out other associated anomalies, particularly in the late second trimester of pregnancy (false-negative rate of $13 \%$ ). The fetuses affected by MVM are typically identified at 19 to 21 weeks, when neurogenesis and migration are not yet complete, $^{43}$ with the consequence that migrational and gyration disorders could be too subtle to be detected with ultrasound. ${ }^{32}$ For this reason, during counseling the parents should be carefully informed about the limitations of ultrasound imaging in differentiating true IMVM from the associated type, and about the possibility that even IMVM can progress in $15.7 \%$ of the cases getting worse prognosis. $^{12}$

When MVM is associated with abnormal karyotype or infection, counseling is less problematic because the concerned cause is known, being able to provide a more accurate prognosis.

In cases associated with CNS anomalies, counseling depends on the type of abnormality carrying different neurological handicaps. ${ }^{44}$ However, there are some CNS anomalies, such as agenesis of corpus callosum whose neurological postnatal outcome is extremely variable, generating conflict decision in the parents. ${ }^{29}$

It is established that the postnatal outcome and neural development are better in children with prenatal IMVM than in those with severe ventricular dilation or VM associated with CNS anomalies. In addition, some authors have suggested that the VM of 10 to $12 \mathrm{~mm}$ can be considered a normal variant especially when it resolves spontaneously. ${ }^{35,37,40}$ On the other hand, Lee et $\mathrm{al}^{45}$ emphasize the concept of a prudent counseling even when ultrasound indicates that the VM is mild, isolated, and nonprogressive since the literature shows variable results in terms of neurodevelopmental outcome $(7.9-12 \%) .{ }^{29}$

Prenatal imaging diagnosis is the pivot for counseling parents whose fetuses have been referred for VM. Because anomalies associated with MVM are not always detected during routine prenatal ultrasound screening, several studies have pointed out the potential role of MRI in the diagnosis of fetal cerebral anomalies and the information that MRI can provide as an adjunctive tool to sonography. ${ }^{46-50}$ In this regard, evidence suggests that the presence of dedicated neurosonography in an ultrasound unit is associated with high sensitivity and specificity for the detection of fetal CNS abnormalities compared with MRI, which however is performed later at 30 to 32 weeks of gestational age. ${ }^{51,52}$

In prenatal counseling, diagnosis of IMVM remains a dilemma: parents should be informed on the need to perform periodic and long-term follow-up extending up to 6 years in the postnatal period to allow early identification of attention deficit and hyperactivity disorders. ${ }^{38}$ A follow-up should be planned according to the diagnosis at birth by an expert pediatrician. Some authors suggest that MRI should be arranged after the age of 1 year to rule out lesions of the white matter that are not detectable during intrauterine or early postnatal life. ${ }^{9}$ 


\section{REFERENCES}

1. Pilu G, Perolo A, Falco P, Visentin A, Gabrielli S, Bovicelli L. Ultrasound of the central nervous system. Curr Opin Obstet Gynecol 2000 Apr;12(2):93-103.

2. International Society of Ultrasound in Obstetrics and Gynecology Education Committee. Sonographic examination of the fetal central nervous system: guidelines for performing the "basic examination" and the "fetal neurosonogram". Ultrasound Obstet Gynecol 2007 Jan;29(1):109-116.

3. Cardoza JD, Goldstein RB, Filly RA. Exclusion of fetal ventriculomegaly with a single measurement: the width of lateral ventricular atrium. Radiology 1988 Dec;169(3):711-714.

4. Guibaud L. Fetal cerebral ventricular measurement and ventriculomegaly: time for procedure standardization. Ultrasound Obstet Gynecol 2009 Aug;34(2):127-130.

5. Pilu G, Falco P, Gabrielli S, Perolo A, Sandri F, Bovicelli L. The clinical significance of fetal isolated cerebral borderline ventriculomegaly: report of 31 cases and review of the literature. Ultrasound Obstet Gynecol 1999 Nov;14(5):320-326.

6. Signorelli M, Tiberti A, Valseriati D, Molin E, Cerri V, Groli C, Bianchi UA. Width of the fetal lateral ventricular atrium between 10 and $12 \mathrm{~mm}$ : a simple variation of the norm? Ultrasound Obstet Gynecol 2004 Jan;23(1):14-18.

7. Bromley B, Frigoletto FD Jr, Benacerraf BR. Mild fetal lateral cerebral ventriculomegaly: clinical course and outcome. Am J Obstet Gynecol 1991 Mar;164(3):863-867.

8. Pagani G, Thilaganathian B, Prefumo F. Neurodevelopmental outcome in isolated mild fetal ventriculomegaly: systematic review and meta-analysis. Ultrasound Obstet Gynecol 2014 Sep;44(3):254-260.

9. Falip C, Blanc N, Maes E, Zaccaria I, Oury JF, Sebag G, Garel C. Postnatal clinical and imaging follow-up of infants with prenatal isolated mild ventriculomegaly: a series of 101 cases. Pediatr Radiol 2007 Oct;37(10):981-989.

10. D'Addario V. The role of ultrasonography in recognizing the cause of fetal cerebral ventriculomegaly. J Perinat Med 2004;32(1):5-12.

11. D'Addario V, Pinto V, Rossi AC, Pintucci A, Di Cagno L. Cavum veli interpositi cyst: prenatal diagnosis and postnatal outcome. Ultrasound Obstet Gynecol 2009 Jul;34(1):52-54.

12. Melchiorre K, Bhide A, Gika AD, Pilu G, Papageorghiou AT. Counseling in isolated mild fetal ventriculomegaly. Ultrasound Obstet Gynecol 2009 Aug;34(2):212-224.

13. Devaseelan P, Cardwell C, Bell B, Ong S. Prognosis of isolated mild to moderate fetal cerebral ventriculomegaly: a systematic review. J Perinat Med 2010 Jul;38(4):401-409.

14. Salomon LJ, Ouahba J, Delezoide AL, Vuillard E, Oury JF, Sebag G, Garel C. Third-trimester fetal MRI in isolated 10- to 12-mm ventriculomegaly: is it worth it? BJOG 2006 Aug;113(8):942-947.

15. Morris JE, Rickard S, Paley MN, Griffiths PD, Rigby A, Whitby $\mathrm{EH}$. The value of in-utero magnetic resonance imaging in ultrasound diagnosed foetal isolated cerebral ventriculomegaly. Clin Radiol 2007 Feb;62(2):140-144.

16. Benacerraf BR, Shipp TD, Bromley B, Levine D. What does magnetic resonance imaging add to the prenatal sonographic diagnosis of ventriculomegaly? J Ultrasound Med 2007 Nov;26(11):1513-1522.

17. Enders G, Bäder U, Lindemann L, Schalasta G, Daiminger A. Prenatal diagnosis of congenital cytomegalovirus infection in 189 pregnancies with known outcome. Prenat Diagn 2001 May;21(5):362-377.
18. Degani S. Sonographic findings in fetal viral infections: a systematic review. Obstet Gynecol Surv 2006 May;61(5):329-336.

19. Picone O, Simon I, Benachi A, Brunelle F, Sonigo P. Comparison between ultrasound and magnetic resonance imaging in assessment of fetal cytomegalovirus infection. Prenat Diagn 2008 Aug;28(8):753-758.

20. Bailão LA, Osborne NG, Rizzi MC, Bonilla-Musoles F, Duarte G, Bailão TC. Ultrasound markers of fetal infection part 1: viral infections. Ultrasound Q 2005 Dec;21(4):295-308.

21. Bailão LA, Osborne NG, Rizzi MC, Bonilla-Musoles F, Duarte G, Bailão TC. Ultrasound markers of fetal infection, part 2: bacterial, parasitic, and fungal infections. Ultrasound Q 2006 Jun;22(2):137-151.

22. Alagappan R, Browning PD, Laorr A, McGahan JP. Distal lateral ventricular atrium: reevaluation of normal range. Radiology 1994 Nov;193(2):405-408.

23. Den Hollander NS, Vinkesteijn A, Schmitz-van Splunder $P$, Catsman-Berrevoets CE, Wladimiroff JW. Prenatally diagnosed fetal ventriculomegaly: prognosis and outcome. Prenat Diagn 1998 Jun;18(6):557-566.

24. Dale ST, Coleman LT. Neonatal alloimmune thrombocytopenia: antenatal and postnatal imaging findings in the pediatric brain. AJNR Am J Neuroradiol 2002 Oct;23(9):1457-1465.

25. Vergani $P$, Locatelli A, Strobelt N, Cavallone M, Ceruti $P$, Paterlini G, Ghidini A. Clinical outcome of mild fetal ventriculomegaly. Am J Obstet Gynecol 1998 Feb;178(2):218-222.

26. Achiron R, Schimmel M, Achiron A, Mashiach S. Fetal mild idiopathic lateral ventriculomegaly: is there a correlation with fetal trisomy? Ultrasound Obstet Gynecol 1993 Mar;3(2):89-92.

27. Van den Hof MC, Wilson RD; Diagnostic Imaging Committee, Society of Obstetricians and Gynaecologists of Canada; Genetics Committee, Society of Obstetricians and Gynaecologists of Canada. Fetal soft markers in obstetric ultrasound. J Obstet Gynaecol Can 2005 Jun;27(6):592-636.

28. Graham E, Duhl A, Ural S, Allen M, Blakemore K, Witter F. The degree of antenatal ventriculomegaly is related to pediatric neurological morbidity. J Matern Fetal Med 2001 Aug;10(4):258-263.

29. D'Addario V. Fetal mild ventriculomegaly: still a challenging problem. J Perinat Med 2015 Jan;43(1):5-9.

30. Gaglioti P, Danelon D, Bontempo S, Mombro M, Cardaropoli S, Todros T. Fetal cerebral ventriculomegaly: outcome in 176 cases. Ultrasound Obstet Gynecol 2005 Apr;25(4):372-377.

31. Ouahba J, Luton D, Vuillard E, Garel C, Gressens P, Blanc N, Elmaleh M, Evrard P, Oury JF. Prenatal isolated mild ventriculomegaly: outcome in 167 cases. BJOG 2006 Sep;113(9):1072-1079.

32. Ball JD, Abuhamad AZ, Mason JL, Burket J, Katz E, Deutsch SI. Clinical outcomes of mild isolated cerebral ventriculomegaly in the presence of other neurodevelopmental risk factors. J Ultrasound Med 2013 Nov;32(11):1933-1938.

33. Emerson E, Hatton C. Mental health of children and adolescent with intellectual disabilities in Britain. Br J Psychiatry 2007 Dec;191:493-499.

34. Lyall AE, Woolson S, Wolfe HM, Goldman BD, Reznick JS, Hamer RM, Lin W, Styner M, Gerig G, Gilmore JH. Prenatal isolated mild ventriculomegaly is associated with persistent ventricle enlargement at ages 1 and 2. Early Hum Dev 2012 Aug;88(8):691-698.

35. Wilhelm C, Keck C, Hess C, Korinthenberg R, Breckwoldt $\mathrm{M}$. Ventriculomegaly diagnosed by prenatal ultrasound and mental development of the children. Fetal Diagn Ther 1998 May-Jun;13(3):162-166. 
36. Kinzler WL, Smulian JC, McLean DA, Guzman ER, Vintzileos AM. Outcome of prenatally diagnosed mild unilateral cerebral ventriculomegaly. J Ultrasound Med 2001 Mar;20(3):257-262.

37. Patel MD, Filly AL, Hersh DR, Goldstein RB. Isolated mild fetal cerebral ventriculomegaly: clinical course and outcome. Radiology 1994 Sep;192(3):759-764.

38. Mercier A, Eurin D, Mercier PY, Verspyck E, Marpeau L, Marret S. Isolated mild fetal cerebral ventriculomegaly: a retrospective analysis of 26 cases. Prenat Diagn 2001 Jul;21(7):589-595.

39. Breeze AC, Dey PK, Lees CC, Hackett GA, Smith GC, Murdoch EM. Obstetric and neonatal outcomes in apparently isolated mild fetal ventriculomegaly. J Perinat Med 2005;33(3):236-240.

40. Lipitz S, Yagel S, Malinger G, Meizner I, Zalel Y, Achiron R. Outcome of fetuses with isolated borderline unilateral ventriculomegaly diagnosed at mid-gestation. Ultrasound Obstet Gynecol 1998 Jul;12(1):23-26.

41. Senat MV, Bernard JP, Schwärzler P, Britten J, Ville Y. Prenatal diagnosis and follow-up of 14 cases of unilateral ventriculomegaly. Ultrasound Obstet Gynecol 1999 Nov;14(5):327-332.

42. Greco P, Vimercati A, De Cosmo L, Laforgia N, Mautone A, Selvaggi L. Mild ventriculomegaly as a counselling challenge. Fetal Diagn Ther 2001 Nov-Dec;16(6):398-401.

43. Graff-Peters VB, Hadders-Algra M. Otogeny of the human central nervous system: What is happening when? Early Hum Dev 2006 Apr;82(4):257-266.

44. Beeghly M, Ware J, Soul J, Du Plessis A, Khwaja O, Senapati GM, Robson CD, Robertson RL, Poussaint TY, Barnewolt $\mathrm{CE}$, et al. Neurodevelopmental outcome of fetuses referred for ventriculomegaly. Ultrasound Obstet Gynecol 2010 April;35(4):405-416.

45. Lee CS, Hong SH, Wang KC, Kim SK, Park JS, Jun JK, Yoon $\mathrm{BH}$, Lee YH, Shin SM, Lee YK, et al. Fetal ventriculomegaly: Prognosis in cases in which prenatal neurosurgical consultation was sought. J Neurosurg 2006 Oct;105 (Suppl 4):265-270.

46. Mehta TS, Levine D. Imaging of fetal cerebral ventriculomegaly: a guide to management and outcome. Semin Fetal Neonatal Med 2005 Oct;10(5):421-428.

47. Garel, C. Ventricular dilatation, in MRI of the fetal brain: normal development and cerebral pathologies. Berlin, Germany: Springer; 2004.

48. Levine D, Trop I, Mehta TS, Barnes PD. MR imaging appearance of fetal cerebral ventricular morphology. Radiology 2002 Jun;223(3):652-660.

49. Levine D, Barnes PD, Madsen JR, Abbott J, Mehta T, Edelman RR. Central nervous system abnormalities assessed with prenatal magnetic resonance imaging. Obstet Gynecol 1999 Dec;94(6):1011-1019.

50. Whitby EH, Paley MN, Sprigg A, Rutter S, Davies NP, Wilkinson ID, Griffiths PD. Comparison of ultrasound and magnetic resonance imaging in 100 singleton pregnancies with suspected brain abnormalities. BJOG 2004 Aug;111(8):784-792.

51. Malinger G, Ben-Sira L, Lev D, Ben-Aroya Z, Kidron D, Lerman-Sage T. Fetal brain imaging: a comparison between magnetic resonance imaging and dedicated neurosonography. Ultrasound Obstet Gynecol 2004 Apr;23(4):333-340.

52. Fulford, J, Gowland, PA. The emerging role of functional MRI for evaluating fetal brain activity. Semin Perinatol 2009 Aug;33(4):281-288. 